\title{
Current guidelines and controversies in the diagnosis and therapy of hypertension in the elderly and very elderly - a review of international recommendations
}

\author{
Piotr Zieleniewicz ${ }^{1,2}$, Tomasz Zdrojewski ${ }^{1}$ \\ 'Department of Preventive Medicine and Education, Faculty of Medicine, Medical University of Gdańsk, Gdańsk, Poland \\ ${ }^{2}$ Department of Cardiology and Electrotherapy, Medical University of Gdańsk, Gdańsk, Poland
}

\begin{abstract}
According to the World Health Organization (WHO) arterial hypertension remains the most important cause of death in the world. Due to ageing of the population and the proven importance of high blood pressure in older age, various expert groups dealing with hypertension worldwide have dedicated more and more separate recommendations to elderly (65-79 years of age) and very elderly patients ( $>80$ years of age). The subject of this work is to present and compare current guidelines for the diagnosis and treatment of hypertension developed for this demographic segment. Due to the global significance in shaping the views on hypertension, the following Englishlanguage guidelines have been used for comparative analyses in this work: 2017 ACC/AHA Guideline, 2018 ESC/ /ESH Guidelines, Hypertension Canada's 2018 Guidelines, 2019 Hypertension in adults: diagnosis and management by National Institute for Health and Care Excellence (NICE), 2016 Guideline for the diagnosis and management of hypertension in adults by National Heart Foundation of Australia. The comparisons have been made based on of blood pressure criteria, the threshold values for drug treatment initiation and the blood pressure target values. In summary, hypertension guidelines for the elderly and very elderly differ significantly, although similar trends in their recommendations are evident.
\end{abstract}

Key words: hypertension; blood pressure; systolic pressure; diastolic pressure; aged; aged, 80 and over; practice guideline

\section{Introduction}

According to the World Health Organization (WHO) arterial hypertension remains the most important cause of death in the world [1]. In view of rapid ageing of societies, it is increasingly important for the clinical practice of primary care physi- cians, cardiologists, nephrologists and geriatricians to establish the principles of hypertension diagnosis and therapy in elderly (over 65 years of age) and very elderly people (above 80 years of age). The population of elderly and very elderly is forecast to double in Poland by 2050 [2]. However, the relatively small number of reports and amount of sci-

Address for correspondence: Piotr Zieleniewicz, MD

Department of Preventive Medicine and Education, Faculty of Medicine, Medical University of Gdańsk, ul. Dębinki 7, 80-211 Gdańsk, Poland, tel: (+48) 5834919 75; e-mail: piotr.zieleniewicz@gumed.edu.pl 
entific evidence regarding the diagnosis and therapy of hypertension in the elderly and very elderly is surprising. Nevertheless, available data confirm that antihypertensive therapy significantly reduces the risk of cardiovascular events and mortality, which has also been proven in the very elderly patients (over 80 years of age) [3-5].

Due to ageing of the population and the proven importance of high blood pressure in older age, various expert groups dealing with hypertension worldwide have dedicated more and more separate recommendations to this demographic segment. Quite unexpectedly, surprising differences in the recommendations from different groups of experts appeared in the last decade. Therefore, the subject of this work is to present and compare current guidelines for the diagnosis and treatment of hypertension developed by various expert groups for elderly and very elderly patients.

\section{History of the diagnosis and treatment of hypertension and beginnings of recommendations for the elderly}

Already in ancient China, Emperor Huang Di in his work "The Yellow Emperor's Classic of Internal Medicine" (circa 2600 BC) describing the anatomy, physiology, pathology, diagnosis and treatment of diseases, as well as preventive medicine, wrote: If too much salt is used in blood, the pulse hardens... [6]. Galen and Hippocrates recommended venesection for the treatment of "hard pulse disease" [7, 8].

The first measurement of blood pressure was carried out by the English pastor Stephen Hales in 1733 , however, the concept of hypertension could enter clinical practice only in 1896 after the Italian internist and pediatrician Scipione Riva-Rocci developed a method of measuring blood pressure using a cuff sphygmomanometer and pulse wave palpation [9]. In 1905, the observation of auscultation phenomena heard through a stethoscope over an artery during a measurement with a sphygmomanometer, described by Nikolai Korotkoff, facilitated the examination of blood pressure and enabled more accurate measurements to be made with systolic and diastolic pressure differentiation [10]. The significance of these measurements was underestimated for several decades and the consequences of untreated elevated blood pressure were not well understood.

Already in 1928 in the Mayo Clinic, the concept of "malignant hypertension" as a syndrome of high blood pressure, severe retinopathy and abnormal kidney function, which led to the patient's death within a year, was developed. In contrast, cases of not so severe hypertension were called "mild" and did not pose a threat in the doctors' opinion at the time. Professor John Hay of the University of Liverpool wrote in 1931: there is some truth in the saying that the greatest danger to a man with a high blood pressure lies in its discovery, because then some fool is certain to try and reduce it [11], and this opinion seemed to be confirmed by the respected American cardiologist, founder of the American Heart Association, Paul Dudley White: Hypertension may be an important compensatory mechanism which should not be tampered with, even were it certain that we could control it... (1937) [12]. In the 1949 textbook "Diseases of the Heart", which was the basis of cardiology of the 1950s and 1960s, Charles Friedberg recommended that people with "mild benign" hypertension... [defined as blood pressures levels of up to $210 / 100 \mathrm{~mm} \mathrm{Hg]...}$ need not be treated [13]. However, verification of these views was prompted by both subsequent data from analyses performed for the needs of insurance companies since the 1930s, in which a relationship between hypertension and increased mortality was observed, as well as, importantly, the premature death of US President Franklin D. Roosevelt due to hemorrhagic stroke in the course of long-term untreated hypertension. In 1948, the American Congress decided to start the first longitudinal study to evaluate the cardiovascular risk over the years - the Framingham Heart Study. It has contributed to a change in the previous views on the essence of "mild" hypertension. The American government institution, the National Institutes of Health, commissioned further population studies, and a group created under its auspices - the Joint National Comission (JNC) - began developing the first guidelines for the treatment of hypertension, which led to the creation of the "First Joint National Committee on Prevention, Detection, Evaluation and Treatment of High Blood Pressure" document in 1977. It was the first of its kind summary of existing knowledge and views on the issue of hypertension. Already in the first update of these recommendations from 1980, there was a separate section devoted to the issue of hypertension in the elderly as a special group of patients [14]. Interestingly, patients over 55 years of age were then considered elderly. That section described the indications for initiating treatment, as well as the methods of optimal pharmacotherapy, and over the years it was successively updated with the publication of the results of the few studies devoted to the elderly and very elderly, including European Working Party on High Blood Pressure in Elderly (EWPHE) in 1989, Systolic Hypertension in the Elderly Program 


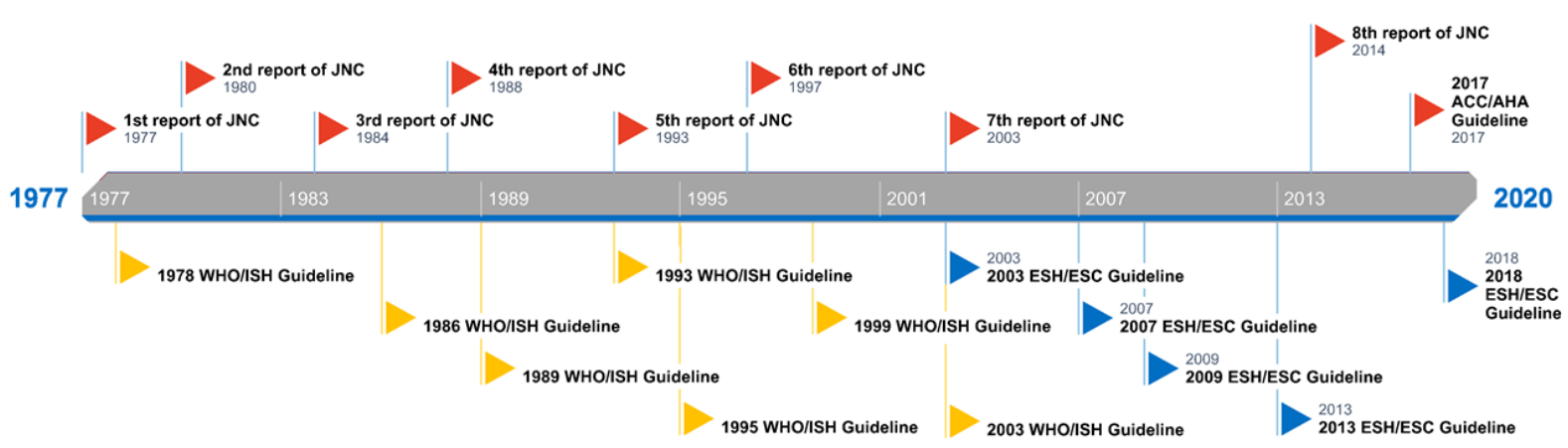

Figure 1. Changes in hypertension guidelines in 1970-2020

(SHEP) in 1991, Systolic Hypertension - Europe Trial (Syst Eur) in 1997, and Hypertension in the Very Elderly Trial (HYVET) in 2008 [15-18]. At the same time, the World Health Organization (WHO) and the International Society of Hypertension (ISH) also worked on their recommendations. These recommendations, published since 1978, laid the foundations for the current guidelines of the European Society of Cardiology (ESC) and the European Society of Hypertension (ESH) (Fig. 1).

\section{Clinical trials evaluating hypertension in the elderly and very elderly}

When developing subsequent sets of guidelines, the authors rely primarily on the published results of clinical trials, but also on the positions of experts and scientific bodies. The amount of scientific evidence is relatively small. In population-based studies evaluating the cardiovascular risk, the subject age has often been limited to less than 70 years of age [19-24], or the population of elderly and very elderly in cross-sectional studies has been increasingly often collectively described as the oldest age group (over 65 years of age) [25-28]. Until now, the health status of the elderly population has been described in only a few nationwide epidemiological studies [29, 30].
In Poland, hypertension in this particular group of patients was first characterized in 1999 [31], and two other Polish studies dedicated to seniors were conducted in the first decade of the $21^{\text {st }}$ century $[32,33]$. These publications are of important value when analyzing trends and changes in the recommendations over the past 20 years. Currently, two large studies focusing on hypertension and the health status of the elderly are underway in Poland - the NOMED-AF [34] and PolSenior 2 studies.

The number of clinical trials that have evaluated this particular group of patients in the context of hypertension has also been small. These include (Fig. 2):

- European Working Party High Blood Pressure in the Elderly (EWHPE), 1986 [15] — the first randomized double-blind study of hypertension in the elderly and very elderly; morbidity and mortality in the population over 60 years of age with blood pressure of 160-239/90-119 mm Hg were evaluated in the combined pharmacotherapy group (hydrochlorothiazide + triamterene) compared to the placebo group; in the pharmacologically treated group, there was a decrease in all-cause mortality (by 26\%) and a decrease in cardiovascular mortality (by 43\%);

- Systolic Hypertension in the Elderly Program (SHEP), 1991 [16] — the first randomized,

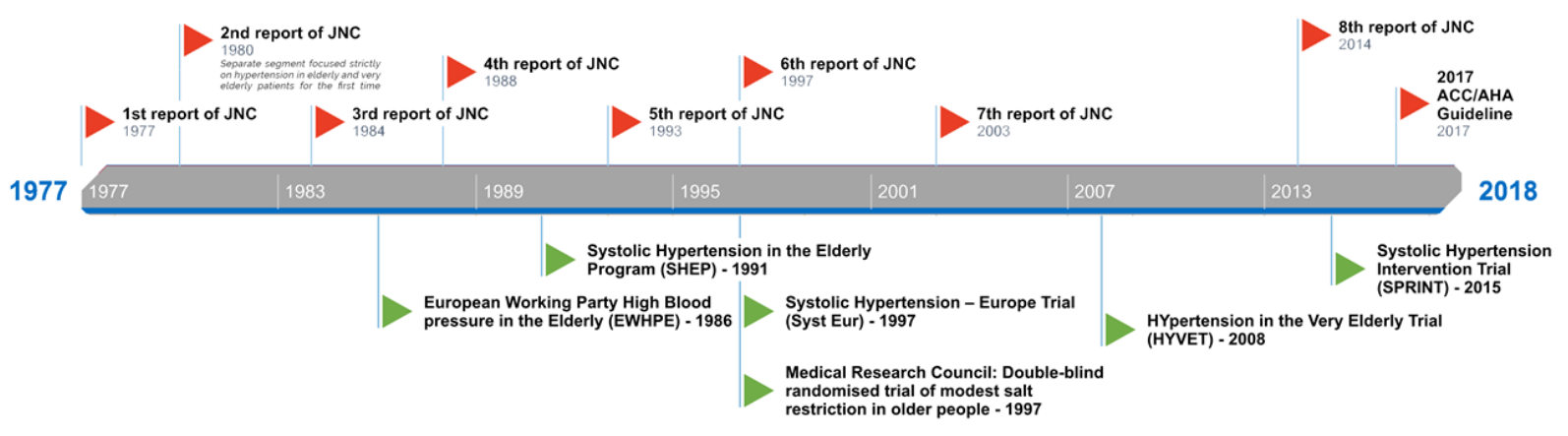

Figure 2. Clinical trials and subsequent guideline updates 
double-blind study that focused on isolated systolic hypertension (ISH); before the SHEP study, justification of ISH treatment was not clear, as it was often considered a "mild" phenomenon that did not require therapy; the study evaluated the effect of pharmacotherapy with chlorthalidone (with the addition of atenolol and reserpine if treatment intensification was needed) on morbidity and mortality in the population over 60 years of age with systolic blood pressure $>160 \mathrm{~mm}$ $\mathrm{Hg}$ (and diastolic pressure $<90 \mathrm{~mm} \mathrm{Hg}$ ); in the pharmacologically treated group, a decrease in stroke rate (by 36\%), cardiovascular disease incidence (by $32 \%$ ), all-cause mortality (by $13 \%$ ), and cardiovascular mortality (by 20\%) was demonstrated;

- Medical Research Council: double-blind randomized trial of modest salt restriction in older people, 1997 [35] — a double-blind randomized study analyzing the effect of a low-sodium diet on average blood pressure in people over 60 years of age; mean blood pressure reduction of 7.2/3.2 $\mathrm{mm} \mathrm{Hg}$ was observed in subjects with moderate sodium intake (an effect comparable to drug therapy with thiazide diuretics), without significant differences between hypertensive and normotensive patients;

- Systolic Hypertension-Europe Trial (Syst Eur), 1997 [17] — another randomized double-blind study that evaluated pharmacotherapy of ISH (nitrendipine, with the addition of enalapril and hydrochlorothiazide if treatment needed to be intensified) in a population over 60 years of age with systolic blood pressure $>160 \mathrm{~mm} \mathrm{Hg}$ (and diastolic blood pressure $<95 \mathrm{~mm} \mathrm{Hg}$ ); in the active treatment group, there was a decrease in stroke rate (by 42\%) and a decrease in the incidence of cardiac endpoints (fatal or non-fatal heart failure, fatal or non-fatal acute coronary syndrome, sudden cardiovascular death) by 26\%;

- Hypertension in the Very Elderly Trial (HYVET), 2008 [18] — the first randomized study of drug therapy of hypertension in the very elderly (over 80 years of age); 3845 participants were included in the study; morbidity and mortality were evaluated in the indapamide treatment group (with the addition of perindopril if treatment needed to be intensified) compared to the placebo group; target blood pressure was < 150/80 mm Hg; statistically significant effects were found in the drug treatment group, including a decrease in stroke rate (by 30\%), heart failure rate (by 64\%), all-cause mortality (by 21\%), cardiovascular mortality (by $23 \%$ ), and mortality from stroke (by 39\%); serious adverse events were more frequently reported in the placebo group (448 vs. 358; $\mathrm{p}=0.001$ );

- Systolic Hypertension Intervention Trial (SPRINT), 2015 [36] — a study evaluating the benefits of intensive reduction of systolic blood pressure compared to "standard treatment" in a group of 9361 non-diabetic patients (in diabetic patients, no significant benefits of intensive blood pressure reduction were demonstrated in the ACCORD study in 2010 [37]), of which 2636 patients ( $28.16 \%$ of the study group) were over 75 years of age; systolic pressure targets were $<120$ $\mathrm{mm} \mathrm{Hg}$ in the intensive group and $<140 \mathrm{~mm} \mathrm{Hg}$ in the "standard treatment" group; intensive treatment resulted in a statistically significant decrease in the rate of the primary outcome (first occurrence of myocardial infarction, acute coronary syndrome, stroke, heart failure, death from cardiovascular causes) (by 25\%), incidence of heart failure (by 38\%), death from cardiovascular causes (by $43 \%$ ) and death from any cause (by $27 \%$ ); differences were also found in the incidence of adverse effects - the incidence of syncope, hypotension, acute kidney injury or acute renal failure was significantly higher in the intensive-treatment group, while orthostatic hypotension was less frequent in the intensive-treatment group and there was no difference in injurious falls.

\section{Contemporary guidelines for the elderly and very elderly in Europe and worldwide}

\section{Similarities and discrepancies regarding blood pressure criteria}

Guidelines are developed by numerous scientific societies around the world, both national and international (Fig. 3). Due to the global significance in shaping the views on hypertension, the following English-language guidelines have been used for comparative analyses in this work:

- 2017 ACC/AHA Guideline for the Prevention, Detection, Evaluation, and Management of High Blood Pressure in Adults [38];

- 2018 ESC/ESH Guidelines for the management of arterial hypertension [39];

- Hypertension Canada's 2018 Guidelines for Diagnosis, Risk Assessment, Prevention, and Treatment of Hypertension in Adults and Children [40];

- 2019 Hypertension in adults: diagnosis and management by National Institute for Health and Care Excellence (NICE) [41]; 


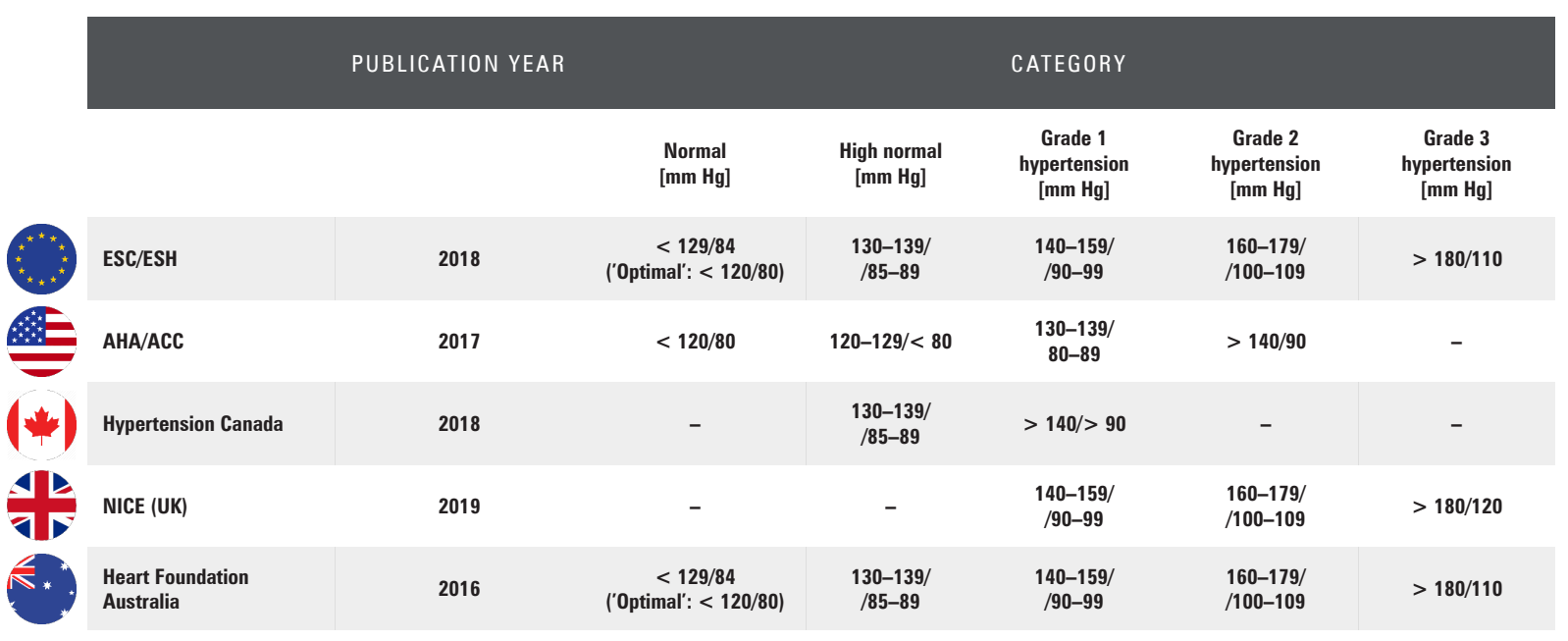

Figure 3. Classification of hypertension in the elderly

- 2016 Guideline for the diagnosis and management of hypertension in adults by National Heart Foundation of Australia [42].

All guidelines unanimously emphasize that the relationship between elevated blood pressure and the cardiovascular risk is continuous and setting specific thresholds for the diagnosis of hypertension is arbitrary. In each of the above guidelines, hypertension has been defined regardless of the patient's age and the definition of hypertension is nearly universal. The commonly accepted threshold for diagnosing hypertension based on office measurements is 140/90 $\mathrm{mm} \mathrm{Hg}$. The ACC/AHA guidelines are the only ones proposing different values, i.e. $130 / 80 \mathrm{~mm} \mathrm{Hg}$. The rationale for this has been an increasing number of studies and meta-analyses showing the above mentioned gradient of increasing cardiovascular risk from normal blood pressure to grade 1 hypertension, as well as a high hazard ratio of stroke and coronary heart disease in patients with blood pressure 130-139/85-89 mm Hg compared to those with blood pressure $<120 / 80 \mathrm{~mm} \mathrm{Hg}$.

The European guidelines also note a graded correlation between hypertension and increasing cardiovascular risk but recognize that the thresholds for diagnosing hypertension must be unequivocal. They have indicated that in the cited meta-analyses, a large group of subjects were classified as grade 1 hypertension while already on drug therapy, and thus they could have originally been diagnosed with a higher grade hypertension. In addition, they have cited the results of a meta-analysis that showed the benefit of treating blood pressure above $140 / 90 \mathrm{~mm} \mathrm{Hg}$, but not lower [43].

Canadian guidelines have explicitly stated: although the CV risk increases at BP levels well below
140/90, this threshold has traditionally been viewed as the point at which (...) treatment could be considered in most patients.

Australian guidelines have also noted the association between increasing blood pressure and increasing cardiovascular risk and the arbitrariness of determining cut-off values. Therefore, they have stated: As a result, cut-off values can vary among international guidelines.

\section{Threshold values for drug treatment initiation}

The authors of the analyzed guidelines have had a consistent view on the issue of determining the cut-off value for initiating drug treatment. To determine this threshold, it is also necessary to consider other burdens for the patient, primarily the cardiovascular risk. Algorithms based on varying parameters, developed and adapted to local populations have been recommended for estimating this threshold (Fig. 4):

- in the ACC/AHA guidelines - 10-year ASCVD (Atherosclerotic Cardiovascular Disease) risk algorithm;

- in the ESC/ESH guidelines - 10-year SCORE (Systemic Coronary Risk Evaluation) risk algorithm;

- in the Hypertension Canada guidelines - 10-year FRS (Framingham Risk Score) algorithm;

- in the NICE guidelines - 10-year QRISK risk algorithm;

- in the recommendations of the National Heart Foundation of Australia - 5-year Australian Absolute cardiovascular disease risk calculator.

Importantly, the guidelines do not differentiate these threshold values between the population aged 18-65 years and the elderly population (65-79 


\begin{tabular}{|c|c|c|c|c|c|}
\hline & 10-year ASCVD risk & 10-year SCORE risk & $\begin{array}{c}\text { 10-year } \\
\text { Framingham Risk } \\
\text { Score }\end{array}$ & 10-year ORISK 3 & $\begin{array}{c}\text { 5-year } \\
\text { Australian absolute } \\
\text { cardiovascular disease } \\
\text { risk }\end{array}$ \\
\hline Guidelines & ACC/AHA & ESC/ESH & Hypertension Canada & NICE & $\begin{array}{c}\text { National Heart } \\
\text { Foundation of Australia }\end{array}$ \\
\hline Age validation & $40-79$ у.о. & $40-65$ у.o. & $30-79$ у.о. & $25-84$ y.o. & $35-74$ у.о. \\
\hline Primary outcome & $\begin{array}{l}\text { Fatal CV event, } \\
\text { myocardial infarction, } \\
\text { stroke }\end{array}$ & Fatal CV event & $\begin{array}{l}\text { Myocardial infarction, } \\
\text { stroke }\end{array}$ & $\begin{array}{l}\text { Myocardial infarction, } \\
\text { stroke }\end{array}$ & Cardiovascular disease \\
\hline \multicolumn{6}{|l|}{ Sex } \\
\hline \multicolumn{6}{|l|}{ Age } \\
\hline \multicolumn{6}{|l|}{ Total cholesterol } \\
\hline \multicolumn{6}{|l|}{ Mean SBP } \\
\hline \multicolumn{6}{|l|}{ Smoking status } \\
\hline \multicolumn{6}{|l|}{ Treated hypertension } \\
\hline \multicolumn{6}{|l|}{ HDL } \\
\hline \multicolumn{6}{|l|}{ Diabetes } \\
\hline Other & & & & $\begin{array}{l}\text { CKD, AF, migraines, RA, SLE, } \\
\text { mental illness, steroid therapy, } \\
\text { erectile dysfunction, BMI }\end{array}$ & ECG LVH \\
\hline
\end{tabular}

Figure 4. Cardiovascular (CV) risk factors in CV risk assessment algorithms. SBP — systolic blood pressure; HDL — high-density lipoprotein; y.o. — years old; CKD — chronic kidney disease; AF — atrial fibrillation; RA — rheumatoid arthritis; SLE — systemic lupus erythematosus; BMI — body mass index; ECG LVH — electrocardiographic left ventricular hypertrophy

\begin{tabular}{|c|c|c|c|}
\hline & PUBLICATION & \multicolumn{2}{|c|}{ TRESHOLD VALUES [mmHg] } \\
\hline & & $65-79$ years old & $80+$ years old \\
\hline ESC/ESH & 2018 & $\begin{array}{l}>140 / 90 \\
>130 / 85 \text { if CAD or stroke/TIA } \\
\text { - should be considered; } \\
>160 / 90 \text { if low CV risk }\end{array}$ & $>160 />90$ \\
\hline AHA/ACC & 2017 & $\begin{array}{c}\quad>\mathbf{1 3 0} />\mathbf{8 0} \\
>140 / 90 \text { if moderate or low CV risk }\end{array}$ & $>130$ \\
\hline Hypertension Canada & 2018 & $\begin{array}{l}>140 / 90 \\
>130 / 80 \text { if high CV risk or DM or over } 75 \text { y.o. } \\
\text { - should be considered; } \\
>160 / 100 \text { if low CV risk }\end{array}$ & $\begin{array}{l}\quad>140 / 90 \\
>130 / 80 \text { if high CV risk or DM or over } 75 \text { y.o. } \\
\text { - should be considered; } \\
>160 / 100 \text { if low CV risk }\end{array}$ \\
\hline NICE (UK) & 2019 & $\begin{array}{c}\quad>160 / 100 \\
>140 / 90 \text { if high CV risk } \\
\text { - should be considered }\end{array}$ & $\begin{array}{c}>\mathbf{1 6 0 / 1 0 0} \\
>150 / 90 \text { - should be considered }\end{array}$ \\
\hline Heart Foundation Australia & 2016 & $\begin{array}{c}>140 / 90 \\
>160 / 90 \text { if low CV risk }\end{array}$ & $\begin{array}{c}>140 / 90 \\
>160 / 90 \text { if low CV risk }\end{array}$ \\
\hline
\end{tabular}

Figure 5. Threshold values for drug treatment initiation. CAD — coronary artery disease; TIA — transient ischemic attack; CV risk — cardiovascular risk; $\mathrm{DM}$ — diabetes mellitus

years of age) (Fig. 5). In all the analyzed guidelines, the authors have had no doubts regarding the treatment of hypertension at $160 / 100 \mathrm{~mm} \mathrm{Hg}$ or higher (160/90 mm Hg in ESC/ESH 2018 guidelines) in each age group, regardless of the estimated cardiovascular risk. The benefits of treating these patients have been proven in many meta-analyses cited by the authors. In contrast, treatment of hypertension in the 140-160 $\mathrm{mm} \mathrm{Hg}$ range has been more complex as the level of cardiovascular risk is of a great importance in these patients. Initiation of drug treatment in this blood pressure range among patients under 80 years of age is generally recommended at a moderate or high cardiovascular 
risk estimated by an appropriate algorithm. The HOPE-3 study provided evidence for the beneficial effect of such an intervention [45]. The exception are the American and Canadian guidelines. They have recommended initiating drug treatment at $130 / 80 \mathrm{~mm} \mathrm{Hg}$ and higher in patients at high and very high cardiovascular risk, and at 140/90 $\mathrm{mm} \mathrm{Hg}$ or higher in patients at moderate risk. The authors of the American guidelines cite the results of HYVET and SPRINT trials, which proved the effectiveness of intensive blood pressure reduction in patients of advanced age and were prematurely discontinued for the benefit of patients in the placebo group. At the same time, it has been noted that according to the NHANES registry, $88 \%$ of Americans over the age of 65 and $100 \%$ of Americans over the age of 75 are at a high cardiovascular risk. Therefore, in the group of very elderly patients $(80+)$, it has been recommended to initiate drug therapy at systolic blood pressure of $130 \mathrm{~mm} \mathrm{Hg}$ or higher without the need for cardiovascular risk assessment, assuming that the latter would most likely be high or very high. Of the other guidelines, treatment initiation in the oldest patients has been recommended at 160/90-100 $\mathrm{mm} \mathrm{Hg}$ (ESC/ESH and NICE UK) or at $140 / 90 \mathrm{~mm} \mathrm{Hg}$ (Hypertension Canada and Heart Foundation Australia). The authors of the European and American guideline have also pointed out that these guidelines apply only to those oldest patients who are relatively fit and independent. The initiation of pharmacotherapy with more than one antihypertensive drug in the very elderly patients is associated with a significant risk of hypotensive episodes, especially orthostatic episodes and falls. Therefore, treatment should be started gradually and at the lowest doses. Initial treatment with two antihypertensive drugs is acceptable but the patient must be closely monitored. Particular caution should be used when treating frail and institutionalized patients. It is also noteworthy that the recommendations of the Canadian and Australian guidelines are the same regardless of the age group and take into account the cardiovascular risk in each of these groups.

\section{Target blood pressure values}

When discussing target blood pressure values, the authors of the guidelines have again cited the results of the HYVET [18] and SPRINT [37] studies. These trials have shown a significant reduction in the cardiovascular morbidity and mortality in the elderly and the very elderly. The SPRINT study also included frail patients. The authors of the American guidelines have noted that until now, no randomized controlled trial has shown harm or less benefit of blood pressure lowering in people over 65 years of age compared to the younger ones. Therefore, there is no need to differentiate target blood pressure values between the elderly and very elderly and the younger patient population (Fig. 6). The AHA/ACC guidelines recommend lowering blood pressure below $130 \mathrm{~mm} \mathrm{Hg}$ in all patients. The authors of the European guidelines have introduced separate targets for younger people and for those over 65 years of age, taking into account significantly more common comorbidities and associated polypharmacotherapy in older patients. They recommend target values in the 130-139/70-79 $\mathrm{mm} \mathrm{Hg}$ range for the elderly pa-

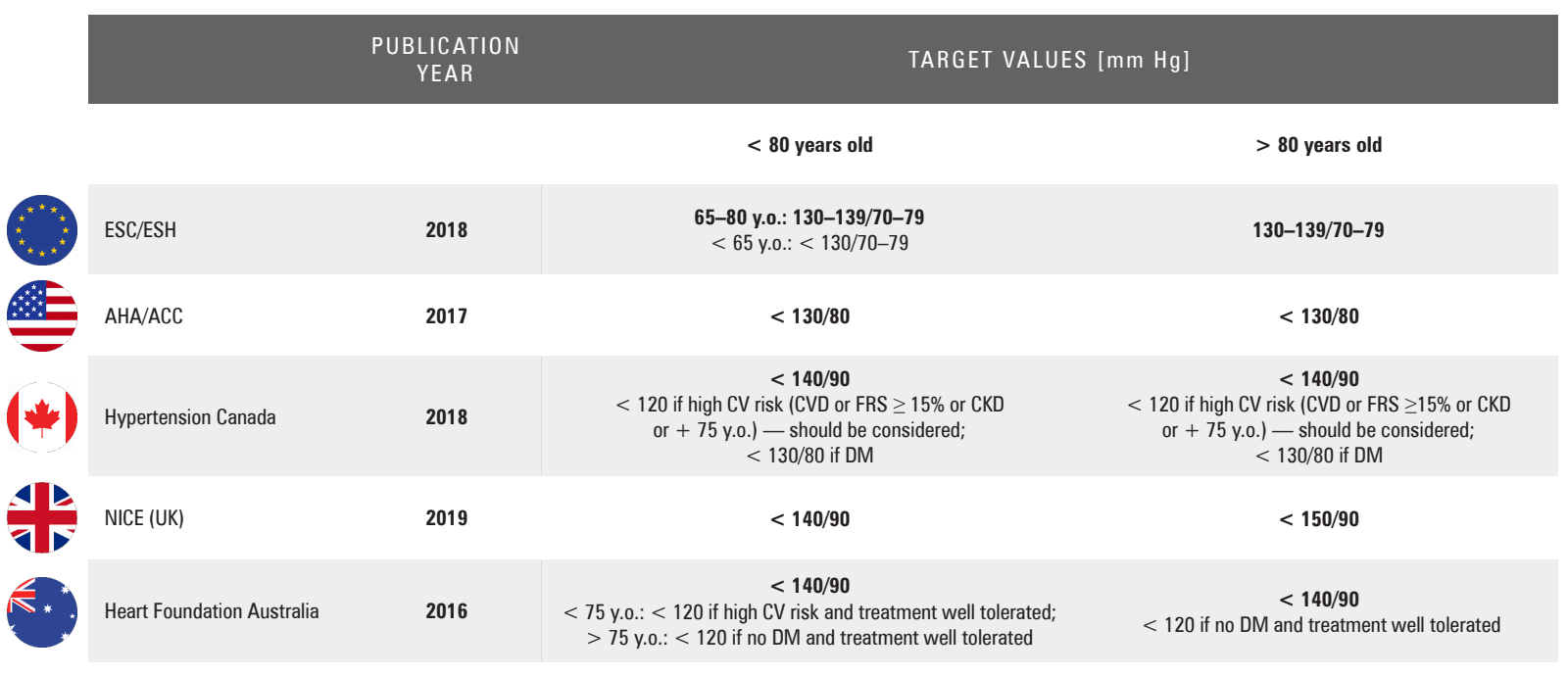

Figure 6. Target blood pressure values for drug treatment. CV risk — cardiovascular risk; CVD — cardiovascular disease; FRS — Framingham Risk Score; CKD — chronic kidney disease; DM — diabetes mellitus; y.o. — years old 
tients, provided that this treatment is well tolerated. At the same time, it has been emphasized that not all patients may achieve these goals, but any blood pressure-lowering effect is beneficial for the patient and associated with a reduction in the cardiovascular risk and mortality. The British guidelines have taken a stance that due to the specific methodology of the SPRINT study, its results are not applicable to the UK population. In accordance with the results of the HYVET study, the target has been defined as $<150 / 90 \mathrm{~mm} \mathrm{Hg}$ in the very elderly and $<140 / 90$ $\mathrm{mm} \mathrm{Hg}$ in patients under 80 years of age. The Australian guidelines, also referring to the HYVET and SPRINT studies, have suggested lowering blood pressure regardless of age even below $120 \mathrm{~mm} \mathrm{Hg}$. Treatment must be well tolerated and undertaken with extreme caution due to a significant increase in the rate of adverse effects with such intensive therapy. However, as the authors argue based on the results of the SPRINT trial, it is beneficial for the patient and leads to a significant reduction in the cardiovascular risk and mortality. The Canadian recommendations are the most diverse among the evaluated guidelines and introduce different target values based on the cardiovascular risk and the presence of chronic kidney disease and diabetes. Importantly, all patients over 75 years of age are considered at a high cardiovascular risk. According to the Canadian authors, systolic blood pressure should be reduced even below $120 \mathrm{~mm} \mathrm{Hg}$ in these patients.

\section{Summary}

Hypertension guidelines for the elderly and very elderly differ significantly, although similar trends in their recommendations are evident. Such a large variety of recommendations can be confusing. However, the choice of the right approach to the diagnosis and treatment of hypertension is always a physician's responsibility according to his or her best and most current knowledge and should be individualized for each patient. The European guidelines cover a very diverse area of the whole of Europe, not always consistent with the specifics of Central and Eastern Europe. It seems useful to assess the epidemiology of hypertension in relation to other recommendations and to contrast them with the current epidemiological indicators based on the European guidelines. Interesting data for such analyses can be provided by the nationwide NOMED-AF and PolSenior 2 studies that focus on assessing the health status of the elderly and very elderly Poles.

\section{References}

1. Forouzanfar MH, Afshin A, Alexander LT, et al. Global, regional, and national comparative risk assessment of 79 behavioural, environmental and occupational, and metabolic risks or clusters of risks, 1990-2015: a systematic analysis for the Global Burden of Disease Study 2015. Lancet. 2016; 388(10053): 1659-724, doi: 10.1016/ S0140-6736(16)31679-8, indexed in Pubmed: 27733284

2. Główny Urząd Statystyczny / Obszary tematyczne / Ludność / Ludność / Struktura ludności. https://stat.gov.pl/obszarytematyczne/ludnosc/ludnosc/ludnosc-w-wieku-60-strukturademograficzna-i-zdrowie,24,1.html (2018 Aug 19).

3. Staessen JA, Gasowski J, Wang JG, et al. Risks of untreated and treated isolated systolic hypertension in the elderly: meta-analysis of outcome trials. Lancet. 2000; 355(9207): 865-872, doi: 10.1016/ s0140-6736(99)07330-4, indexed in Pubmed: 10752701.

4. Bejan-Angoulvant T, Saadatian-Elahi M, Wright JM, et al. Treatment of hypertension in patients 80 years and older: the lower the better? A meta-analysis of randomized controlled trials. J Hypertens. 2010; 28(7): 1366-1372, doi: 10.1097/HJH.0b013e328339f9c5, indexed in Pubmed: 20574244.

5. Beckett N, Peters R, Fletcher A, et al. Treatment of Hypertension in Patients 80 Years of Age or Older. N Eng J Med. 2008; 358(18): 1887-1898, doi: 10.1056/nejmoa0801369, indexed in Pubmed: 18378519 .

6. Veith I. The Yellow Emperor's classic of internal medicine. Chapters 1-34. University of California Press, Berkeley 2002: 260.

7. Hippocrates. The Genuine Works of Hippocrates. W Wood, New York 1886: 493.

8. Galen G. Claudii Galeni Pergameni Introductio in Pulsus Ad Teuthram. Latin Edit. Forgotten Books, London 2018: 96.

9. Riva-Rocci S. Un nuovo sfigmomanometro. Gazz medica, Torino 1896: 1001-1017.

10. Korotkoff NSA. contribution to the problem of methods for the determination of blood pressure Rep. Imp Mil Med Acad (St Petersburg). 1905; 11: 365-367.

11. Hay J. A British Medical Association Lecture on the significance of a raised blood pressure. Br Med J. 1931; 2(3679): 43-47, doi: 10.1136/bmj.2.3679.43, indexed in Pubmed: 20776269.

12. Dudley White P. Heart disease. 2nd ed. The Macmillan Company, New York 1937.

13. Friedberg CK. Diseases of the Heart. Saunders, Philadelphia 1949: 1081.

14. The 1980 report of the Joint National Committee on Detection, Evaluation, and Treatment of High Blood Pressure. Arch Intern Med. 1980; 140(10): 1280-1285, indexed in Pubmed: 6775608.

15. Staessen J, Bulpitt C, Clement D, et al. Relation between mortality and treated blood pressure in elderly patients with hypertension: report of the European Working Party on High Blood Pressure in the Elderly. BMJ. 1989; 298(6687): 1552-1556, doi: 10.1136/ bmj.298.6687.1552, indexed in Pubmed: 2503114.

16. Prevention of stroke by antihypertensive drug treatment in older persons with isolated systolic hypertension. Final results of the Systolic Hypertension in the Elderly Program (SHEP). SHEP Cooperative Research Group. JAMA. 1991; 265(24): 3255-3264, indexed in Pubmed: 2046107.

17. Staessen JA, Fagard R, Thijs L, et al. Randomised double-blind comparison of placebo and active treatment for older patients with isolated systolic hypertension. The Systolic Hypertension in Europe (Syst-Eur) Trial Investigators. Lancet. 1997; 350(9080): 757-764, doi: 10.1016/s0140-6736(97)05381-6, indexed in Pubmed: 9297994.

18. Beckett N, Peters R, Fletcher A, et al. Treatment of Hypertension in Patients 80 Years of Age or Older. New England Journal of Medicine. 2008; 358(18): 1887-1898, doi: 10.1056/nejmoa0801369.

19. Antikainen RL, Kastarinen MJ, Jousilahti P, et al. Despite evidence-based guidelines, systolic blood pressure remains inadequately controlled in older hypertensive adults. J Hum Hypertens. 2010; 24(7): 439-446, doi: 10.1038/jhh.2009.85, indexed in Pubmed: 19890369 . 
20. Guessous I, Bochud M, Theler JM, et al. 1999-2009 Trends in prevalence, unawareness, treatment and control of hypertension in Geneva, Switzerland. PLoS One. 2012; 7(6): e39877, doi: 10.1371/ journal.pone.0039877, indexed in Pubmed: 22761919.

21. Joffres M, Falaschetti E, Gillespie C, et al. Hypertension prevalence, awareness, treatment and control in national surveys from England, the USA and Canada, and correlation with stroke and ischaemic heart disease mortality: a cross-sectional study. BMJ Open. 2013; 3(8): e003423, doi: 10.1136/bmjopen-2013-003423, indexed in Pubmed: 23996822.

22. Leenen FHH, Dumais J, McInnis NH, et al. Results of the Ontario survey on the prevalence and control of hypertension. CMAJ. 2008; 178(11): 1441-1449, doi: 10.1503/cmaj.071340, indexed in Pubmed: 18490640.

23. Neuhauser HK, Adler C, Rosario AS, et al. Hypertension prevalence, awareness, treatment and control in Germany 1998 and 2008-11. J Hum Hypertens. 2015; 29(4): 247-253, doi: 10.1038/jhh.2014.82, indexed in Pubmed: 25273858.

24. Zdrojewski Ł, Rutkowski M, Bandosz P, et al. Prevalence and control of cardiovascular risk factors in Poland. Assumptions and objectives of the NATPOL 2011 Survey. Kardiol Pol. 2013; 71(4): 381-392, doi: 10.5603/KP.2013.0066, indexed in Pubmed: 23788344.

25. Falaschetti E, Chaudhury M, Mindell J, et al. Continued improvement in hypertension management in England: results from the Health Survey for England 2006. Hypertension. 2009; 53(3): 480-486, doi: 10.1161/HYPERTENSIONAHA.108.125617, indexed in Pubmed: 19204180.

26. De Macedo ME, Lima MJ, Silva AO, et al. Prevalence, awareness, treatment and control of hypertension in Portugal: the PAP study. J Hypertens. 2005; 23(9): 1661-1666, doi: 10.1097/01. hjh.0000179908.51187.de, indexed in Pubmed: 16093910.

27. Psaltopoulou T, Orfanos P, Naska A, et al. Prevalence, awareness, treatment and control of hypertension in a general population sample of 26,913 adults in the Greek EPIC study. Int J Epidemiol. 2004; 33(6): 1345-1352, doi: 10.1093/ije/dyh249, indexed in Pubmed: 15218014.

28. Yoon SS, Gu Q, Nwankwo T, et al. Trends in blood pressure among adults with hypertension: United States, 2003 to 2012. Hypertension. 2015; 65(1): 54-61, doi: 10.1161/HYPERTENSIONAHA.114.04012, indexed in Pubmed: 25399687.

29. McDonald M, Hertz RP, Unger AN, et al. Prevalence, awareness, and management of hypertension, dyslipidemia, and diabetes among United States adults aged 65 and older. J Gerontol A Biol Sci Med Sci. 2009; 64(2): 256-263, doi: 10.1093/gerona/gln016, indexed in Pubmed: 19181717.

30. Jacobs JM, Stessman J, Ein-Mor E, et al. Hypertension and 5-year mortality among 85-year-olds: the Jerusalem Longitudinal Study. J Am Med Dir Assoc. 2012; 13(8): 759.e1-759.e6, doi: 10.1016/j. jamda.2012.05.005, indexed in Pubmed: 22698954.

31. Kąkol M, Zdrojewski T, Kąkol-Kozicka K. Rozpowszechnienie, świadomość oraz skuteczność leczenia nadciśnienia tętniczego u ludzi starszych w Polsce ocena metodą sondażu reprezentatywnego. Gerontol Pol. 1999; 7: 23-9.

32. Broda G, Piotrowski W, Bandosz P. et al. Badanie WOBASZ Senior — ocena epidemiologii czynników ryzyka chorób serca i naczyń u starszych Polaków. . In: Kopeć G, Jankowski P, Pająk A. et al. ed. Epidemiologia i prewencja chorób układu krążenia. 1st ed. Medycyna Praktyczna, Kraków 2015: 93-99.

33. Zdrojewski T, Wizner B, Więcek A, et al. Prevalence, awareness, and control of hypertension in elderly and very elderly in Poland: results of a cross-sectional representative survey. J Hypertens. 2016; 34(3): 532-8; discussion 538, doi: 10.1097/HJH.0000000000000823, indexed in Pubmed: 26771343.

34. Kalarus Z, Balsam P, Bandosz P, et al. NOninvasive Monitoring for Early Detection of Atrial Fibrillation: rationale and design of the NOMED-AF study. Kardiol Pol. 2018; 76(10): 1482-1485, doi: 10.5603/KP.a2018.0193, indexed in Pubmed: 30211437.

35. Cappuccio FP, Markandu ND, Carney C, et al. Double-blind randomised trial of modest salt restriction in older people. Lancet. 1997; 350(9081): 850-854, doi: 10.1016/S0140-6736(97)022642, indexed in Pubmed: 9310603.

36. Wright JT, Williamson JD, Whelton PK, et al. SPRINT Research Group. A Randomized Trial of Intensive versus Standard BloodPressure Control. N Engl J Med. 2015; 373(22): 2103-2116, doi: 10.1056/NEJMoa1511939, indexed in Pubmed: 26551272.

37. Cushman WC, Evans GW, Byington RP, et al. ACCORD Study Group. Effects of intensive blood-pressure control in type 2 diabetes mellitus. N Engl J Med. 2010; 362(17): 1575-1585, doi: 10.1056/ NEJMoa1001286, indexed in Pubmed: 20228401.

38. Whelton P, Carey R, Aronow W, et al. 2017 ACC/AHA/AAPA/ ABC/ACPM/AGS/APhA/ASH/ASPC/NMA/PCNA Guideline for the Prevention, Detection, Evaluation, and Management of High Blood Pressure in Adults. J Am Coll Cardiol. 2018; 71(19): e127-e248, doi: 10.1016/j.jacc.2017.11.006, indexed in Pubmed: 29146535.

39. Williams B, Mancia G, Spiering W, et al. ESC Scientific Document Group . 2018 ESC/ESH Guidelines for the management of arterial hypertension. Eur Heart J. 2018; 39(33): 3021-3104, doi: 10.1093/ eurheartj/ehy339, indexed in Pubmed: 30165516.

40. Nerenberg KA, Zarnke KB, Leung AA, et al. Hypertension Canada's 2018 Guidelines for Diagnosis, Risk Assessment, Prevention, and Treatment of Hypertension in Adults and Children. Can J Cardiol. 2018; 34(5): 506-25, doi: 10.1016/j.cjca.2018.02.022, indexed in Pubmed: 29731013.

41. National Institute for Health and Care Excellence (NICE). Hypertension in adults: diagnosis and management. NICE Guidelines 2019. https://www.nice.org.uk/guidance/ng136.

42. National Heart Foundation of Australia. Guideline for the diagnosis and management of hypertension in adults - 2016. National Heart Foundation of Australia, Melbourne 2016: 84.

43. Brunström M, Carlberg Bo. Association of Blood Pressure Lowering With Mortality and Cardiovascular Disease Across Blood Pressure Levels: A Systematic Review and Meta-analysis. JAMA Intern Med. 2018; 178(1): 28-36, doi: 10.1001/jamainternmed.2017.6015, indexed in Pubmed: 29131895.

44. Lonn EM, Bosch J, López-Jaramillo P, et al. HOPE-3 Investigators. Blood-Pressure Lowering in Intermediate-Risk Persons without Cardiovascular Disease. N Engl J Med. 2016; 374(21): 2009-2020, doi: 10.1056/NEJMoa1600175, indexed in Pubmed: 27041480. 